\title{
Salvage radiotherapy improves survival in patients with locoregionally relapsed stage IE-IIE extranodal natural killer/T-cell lymphoma, nasal type
}

This article was published in the following Dove Press journal:

Therapeutics and Clinical Risk Management

\author{
Qin Tongl,* \\ Shuming Ouyang ${ }^{2, *}$ \\ Lingling Feng,* \\ Hanyu Wang ${ }^{3}$ \\ Yunfei $\mathrm{Xia}^{3}$ \\ Yujing Zhang ${ }^{3}$ \\ 'Department of Radiation Oncology, \\ The First Affiliated Hospital of \\ University of South China, Hengyang \\ 42100I, People's Republic of China; \\ ${ }^{2}$ Department of Obstetrics and \\ Gynecology, The First Affiliated \\ Hospital of University of South \\ China, Hengyang 42I00I, People's \\ Republic of China; ${ }^{3}$ Department of \\ Radiation Oncology, Sun Yat-sen \\ University Cancer Center, State Key \\ Laboratory of Oncology in South \\ China, Guangzhou 510060, People's \\ Republic of China \\ *These authors contributed equally \\ to this work
}

Background: This study aims to retrospectively analyze the salvage treatment outcomes and prognostic factors of patients with early stage locoregionally recurrent (LRR) extranodal natural killer (NK)/T-cell lymphoma, nasal type (ENKTCL).

Methods: Between January 1995 and December 2014, 540 patients with stage IE-IIE ENKTCL received chemotherapy (ChT) and/or radiotherapy (RT) in our hospital, and among these, 56 patients who experienced LRR were included in this study. Salvage treatments included RT alone in 4 patients (7.1\%), ChT alone in 30 patients (53.6\%), and ChT combined with RT in 22 patients (39.3\%). Median RT dose was 50 Gy (range 36-60 Gy). The effect of salvage treatment on overall survival (OS) rate from start of initial treatment (IT) as well as that after recurrence was analyzed.

Results: The overall median follow-up time from IT was 35.9 months, with a 3-year OS of $72.7 \%$. The median follow-up time after relapse was 14.8 months, and the 3-year OS after relapse was $57.8 \%$. Compared to ChT alone $(n=30)$, treatment with salvage RT $(n=26)$ improved the OS from IT ( $p=0.040)$ and after relapse ( $p=0.009)$; further, re-irradiation improved the OS from IT $(p=0.018)$ and after relapse $(p=0.019)$. Acute and late toxicities after re-irradiation were mostly grades $1-2(84.3 \%)$. At both univariate and multivariate analyses, better Karnofsky Performance Score (KPS), RT in IT, and RT in salvage treatment were found to be significant factors influencing OS after recurrence.

Conclusion: Salvage RT improved survival in patients with LRR stage IE-IIE ENKTCL, and the treatment toxicity was acceptable.

Keywords: extranodal NK/T-cell lymphoma, nasal type, radiotherapy, recurrence, prognostic analysis

\section{Introduction}

Extranodal natural killer (NK)/T-cell lymphoma, nasal type (ENKTCL) is an independent pathological type of non-Hodgkin's lymphoma. Globally, it is much more common in Asia and Latin America than in other areas. This disease is usually observed in young to middle-aged males, diagnosed at an early stage, and exhibits a close association with Epstein-Barr virus infection. The common primary site of this disease is the upper aerodigestive tract (UADT), especially the nasal cavity and Waldeyer's ring.

In recent years, with higher dose and extended involved-field radiotherapy (RT), alone or in combination with chemotherapy (ChT), the 5-year overall survival (OS) rate for early stage ENKTCL has increased to $71.2 \%-86 \% .{ }^{1-3}$ The overall failure rate is approximately $20.7 \%-32.9 \%$, of which the distant metastasis rate is $11.3 \%-25.5 \%$ and
Correspondence: Yujing Zhang Department of Radiation Oncology, Sun Yat-sen University Cancer Center, State Key Laboratory of Oncology in South China, 65I Dongfeng Road East, Guangzhou, Guangdong 510060 , People's Republic of China Tel +86 I37 I060 8235 Email zhangyj@sysucc.org.cn 
the locoregional relapse rate is $7.5 \%-16.9 \% .^{2,4,5}$ Currently, there are limited studies on the survival and prognosis of patients with locoregional relapse, and the salvage strategies have not yet been established. To provide a basis for clinical treatment, this study aimed to retrospectively analyze the efficacy and prognostic factors of salvage treatment in early stage ENKTCL with locoregional relapse.

\section{Methods}

\section{Patient eligibility and evaluation}

The inclusion criteria were as follows: 1) primary ENKTCL of the UADT; 2) Ann Arbor stage of the primary lesion of IE-IIE; 3) initially treated with ChT and/or RT; 4) diseasefree survival after initial treatment (IT) of at least 3 months; 5 ) initial progression of only locoregional relapse; and 6) received salvage $\mathrm{ChT}$ and/or RT after relapse. Cases with concurrent distant metastasis were not included.

All cases were diagnosed according to the criteria of the World Health Organizations classification of lymphomas. Biopsies were carried out in all patients to confirm both the initial diagnosis and relapse. The clinical examination included a routine physical and laboratory examination, head and neck CT or MRI, chest and abdomen pelvis CT, and bone marrow examination, and some patients completed $\mathrm{PET} / \mathrm{CT}$ examination.

\section{Initial treatment}

One case was treated with RT alone (1.8\%), 18 cases were treated with ChT alone (32.1\%), and 37 cases were treated with the combination of RT and ChT (66.1\%). Conventional fractionation was used for RT with a median dose of $51.3 \mathrm{~Gy}$ (36-68 Gy), of which 1 case received $<40$ Gy and 6 cases received 40-49 Gy. Twenty cases $(52.6 \%)$ were treated with 3-dimensional or intensity-modulated RT, and 18 cases received conventional RT. Local extended field RT was performed (Figure 1). ${ }^{6,7}$ For ChT regimens, 48 patients $(87.3 \%)$ were treated with CHOP (cyclophosphamide, doxorubicin, vincristine, prednisone) or CHOP-like (CHOP plus etoposide or bleomycin) protocols, and 7 patients (12.7\%) received L-asparaginase-based regimens as first-line treatment. The median number of ChT cycles was 4 (range: 1-9).

\section{Salvage therapy}

Four cases were treated with RT alone (7.1\%), 30 cases were treated with ChT alone (53.6\%), and 22 cases were treated with RT and ChT (39.3\%). Conventional fractionation was used for RT with a median dose of $50 \mathrm{~Gy}$ (36-60 Gy), of which 3 cases received $<40$ Gy and 5 cases received 40-49 Gy. Twenty-one patients (82.3\%) underwent 3-dimensional or intensity-modulated RT, and 5 patients received conventional RT. RT of the involved field was performed (Figure 2). Re-irradiation was administered in 19 cases (13 cases of in-field relapse and 6 cases of outfield and edged relapse). The median dose of re-irradiation was 50 Gy (36-60 Gy), including 1 case with $<40$ Gy and 2 cases with 40-49 Gy. The remission (complete remission $[\mathrm{CR}]+$ partial remission $[\mathrm{PR}]$ ) rate of re-irradiation was $100 \%$. The most commonly used salvage ChT regimens were IMVP-16 (ifosfamide, mesna, methotrexate, and etoposide) or a regimen containing L-asparaginase, with the median of 5 (range: 1-9) cycles.

\section{Analysis of indicators}

The OS time from IT and OS time after relapse were defined as the time from the first day of treatment and the first day of the diagnosis of relapse, respectively, to the patient's death
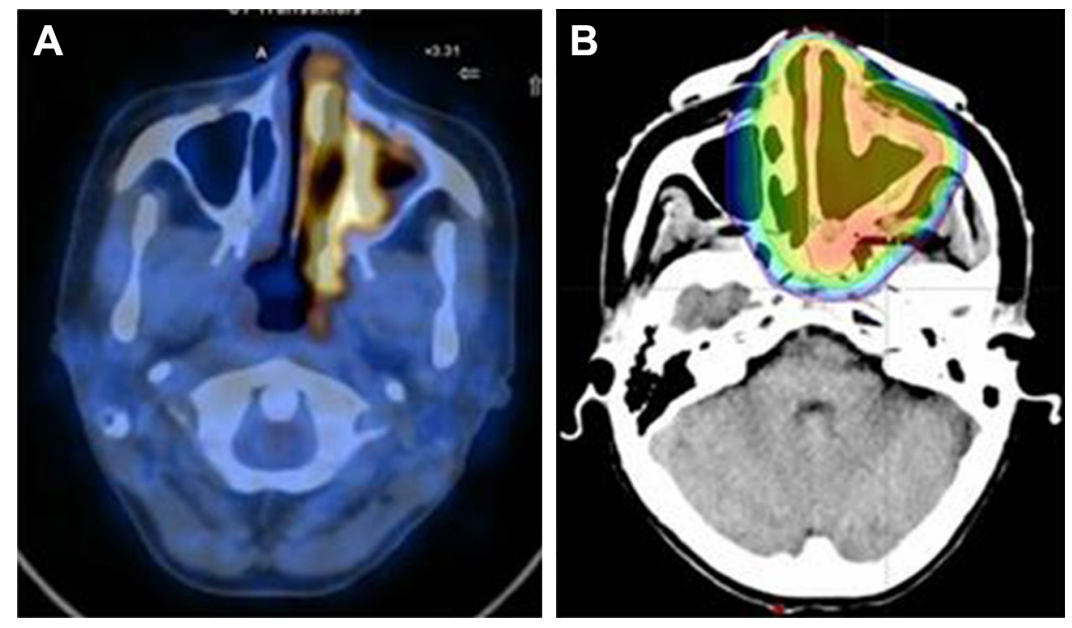

Figure I Primary nasal natural killer/T lymphoma.

Notes: PET/CT scan before initial treatment (A), target (line), and dose profile (dose color wash) for radiotherapy (B) after 3 cycles of induction chemotherapy. 

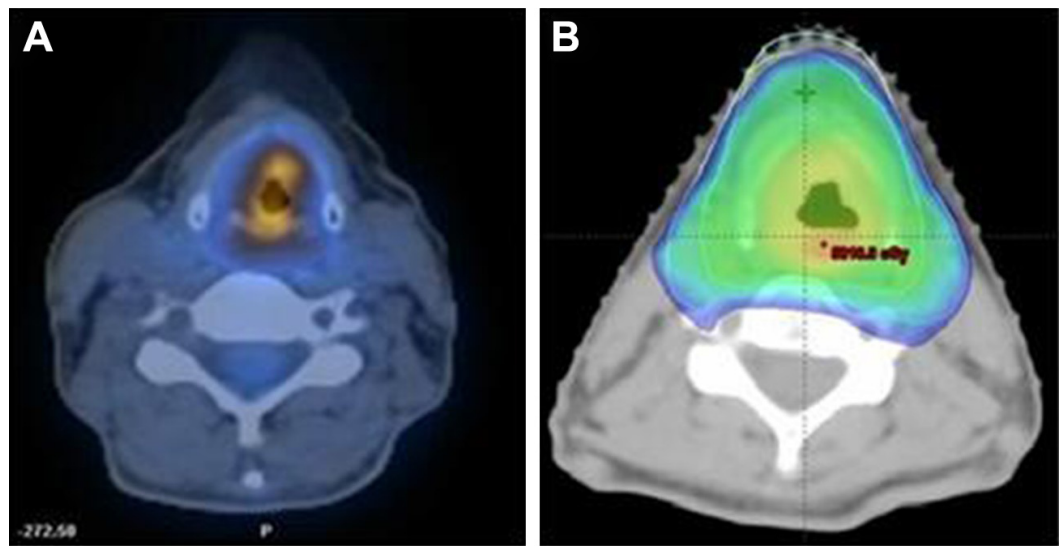

Figure 2 Laryngeal relapsed natural killer/T lymphoma in patient in Figure I after 13 months from initial treatment.

Notes: PET/CT scan before salvage treatment (A), target (line), and dose profile (dose color wash) for salvage radiotherapy (B).

from any cause or to the date of ending follow-up. Acute and late toxicities were assessed using RTOG criteria. The efficacy was evaluated using the International Working Group criteria for lymphoma. ${ }^{8}$ The prognostic factors included sex, age, B symptoms, primary site, extensive local tumor invasion, lactate dehydrogenase (LDH) group, Ann Arbor stage, Karnofsky Performance Score (KPS), IT with or without RT, CR or not after IT, salvage treatment with or without RT, and duration of remission after IT.

\section{Statistical methods}

The survival data were calculated using the Kaplan-Meier method. In univariate analysis, survival curves were compared by the log-rank test. Multivariate analysis was carried out using the Cox regression model. Patient characteristics were compared by the chi-squared test or Fisher's exact test. $p<0.05$ was considered statistically significant. All these statistical analyses were performed with IBM SPSS software 19.0.

\section{Ethical approval}

This study was approved by the Ethics Committee of Sun Yat-sen University Cancer Center, and patients' written informed consent was obtained.

\section{Results}

From 1995 to 2014, 540 patients with early stage primary UADTNK/T-cell lymphoma were treated in Sun Yat-sen University Cancer Center. A total of 110 cases had locoregional relapse with or without distant metastasis, of which 56 cases qualified for the criteria of this study, accounting for $10.3 \%$ of all patients.

\section{Characteristics of overall cases}

The primary clinical features of the 56 patients with relapse at IT are listed in Table 1. The pattern of locoregional relapse included local relapse in 43 patients (76.8\%), regional lymph node relapse in 2 patients (3.6\%), and both local and regional lymph node relapse in 11 patients $(19.6 \%)$. The median time for relapse was 15.4 months (range: 3.2-235.7 months). A total of 44 patients $(78.6 \%)$ relapsed in 2 years, and 6 patients $(10.8 \%)$ relapsed after 5 years of treatment.

Table I Primary clinical features of 56 patients with LRR ENKTCL who received salvage treatment with or without salvage RT

\begin{tabular}{|c|c|c|c|c|}
\hline $\begin{array}{l}\text { Clinical } \\
\text { features }\end{array}$ & Number & $\begin{array}{l}\text { With } \\
\text { salvage RT }\end{array}$ & $\begin{array}{l}\text { ChT } \\
\text { alone }\end{array}$ & $\begin{array}{l}\text { p-value } \\
\left(\chi^{2}\right)\end{array}$ \\
\hline Sex & & & & 0.399 \\
\hline Male & 38 & 16 & 22 & \\
\hline Female & 18 & 10 & 8 & \\
\hline Age & & & & 1.000 \\
\hline$\leq 60$ years & 49 & 23 & 26 & \\
\hline$>60$ years & 7 & 3 & 4 & \\
\hline B symptoms & & & & 0.421 \\
\hline Yes & 30 & 12 & 18 & \\
\hline No & 26 & 14 & 12 & \\
\hline Primary sites & & & & 0.779 \\
\hline Nasal cavity & 37 & 18 & 19 & \\
\hline Others & 19 & 8 & II & \\
\hline ELTI & & & & 1.000 \\
\hline Yes & 26 & 12 & 14 & \\
\hline No & 30 & 14 & 16 & \\
\hline $\mathrm{LDH}$ & & & & 0.412 \\
\hline Elevated & 21 & 8 & 13 & \\
\hline Normal & 35 & 18 & 17 & \\
\hline $\begin{array}{l}\text { Ann Arbor } \\
\text { stage }\end{array}$ & & & & 0.365 \\
\hline $\mathrm{IE}$ & $4 I$ & 21 & 20 & \\
\hline IIE & 15 & 5 & 10 & \\
\hline KPS score & & & & 0.240 \\
\hline 70 & 3 & 0 & 3 & \\
\hline$\geq 80$ & 53 & 26 & 27 & \\
\hline
\end{tabular}

Abbreviations: ChT, chemotherapy; ELTI, extensive local tumor invasion; ENKTCL, extranodal natural killer/T-cell lymphoma, nasal type; KPS, Karnofsky Performance Score; LDH, lactate dehydrogenase; LRR, locoregionally recurrent; RT, radiotherapy. 

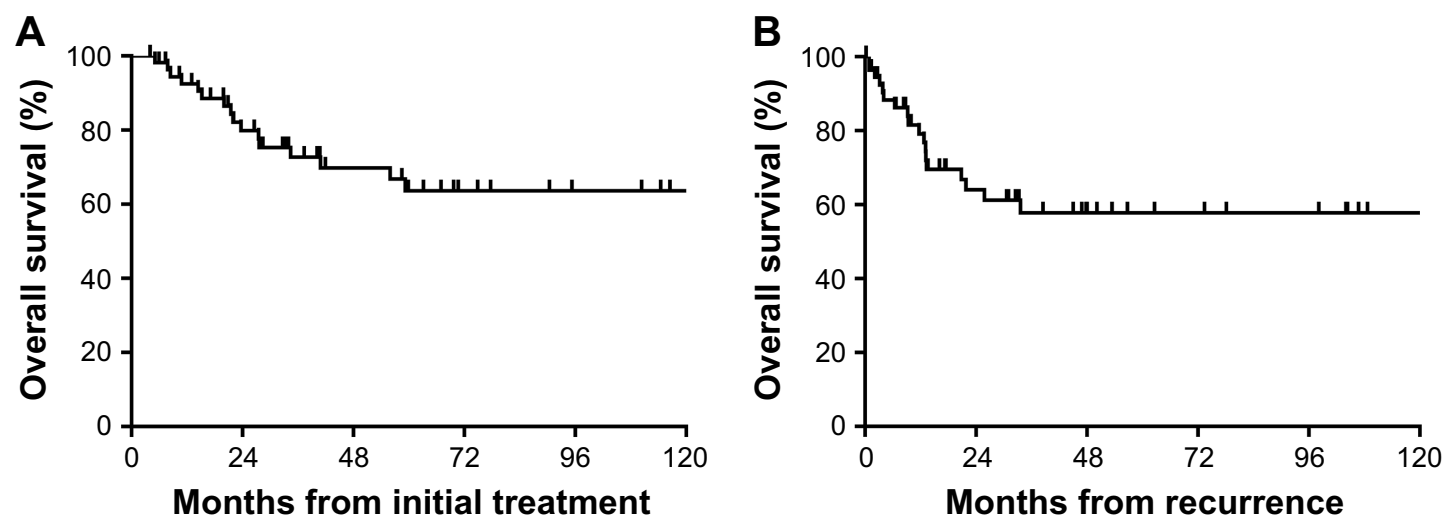

Figure 3 Overall survival rates after initial treatment $(\mathbf{A})$ or after recurrence $(\mathbf{B})$ in 56 patients with relapsed extranodal natural killer/T-cell lymphoma, nasal type.

\section{OS from initial treatment and after relapse} The overall median follow-up time from IT was 35.9 months. The overall 2-year and 3-year survival rates from IT were $79.9 \%$ and $72.7 \%$, respectively. The median follow-up time after relapse was 14.8 months. The overall 2-year and 3-year survival rates after relapse were $64.0 \%$ and $57.8 \%$, respectively (Figure 3). A total of 18 patients died during the follow-up period, of which 17 patients died of ENKTCL progression (uncontrolled locoregional area in 9 cases, distant metastasis in 6 cases, and hemophagocytic syndrome in 2 cases), and 1 died of a cardiac stent implantation infection.

\section{The impact of salvage treatment with or without RT on survival}

Of the 56 relapse patients, 26 were treated with salvage RT, and 30 were treated with $\mathrm{ChT}$ alone. There was no significant difference in clinical characteristics between the 2 groups (Table 1). The overall median follow-up time from IT and after relapse was 65 months and 41.8 months, respectively, for the salvage RT group. The overall 2-year and 3-year

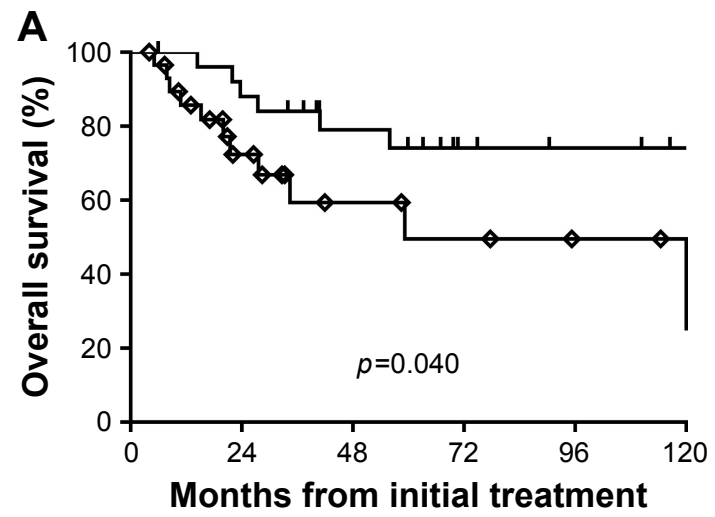

survival rates from IT were $88.0 \%$ and $84.0 \%$, respectively. The overall 2-year and 3-year survival rates after relapse were $79.9 \%$ and $70.7 \%$, respectively. The overall median follow-up time of the ChT only group from IT and after relapse was 21.8 months and 7.5 months, respectively. The overall 1-year and 2-year survival rates of this group from IT were $85.7 \%$ and $72.4 \%$, respectively. The overall 1 -year and 2-year survival rates after relapse were $57.8 \%$ and $41.1 \%$, respectively. Compared to the ChT only group, the OS from IT $(p=0.040)$ (Figure 4A) and after relapse $(p=0.009)$ (Figure 4B) of the salvage RT group was improved.

\section{The impact of re-irradiation in the salvage treatment on survival}

In total, 38 patients received RT in IT, of which 19 cases received re-irradiation after relapse, and other 19 cases received ChT alone. No significant difference was observed in clinical characteristics between the 2 groups (Table 2). The median follow-up time from IT and after relapse were 70.7 months and 46.9 months, respectively, for the re-irradiation group,

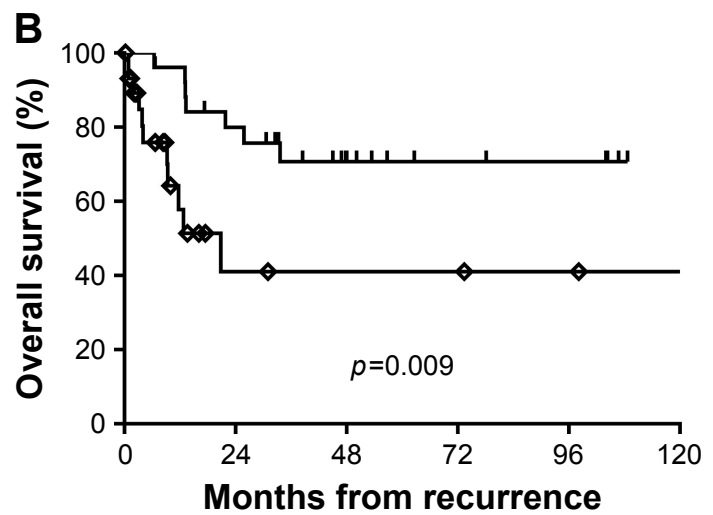


Table 2 Comparison of clinical characteristics in 38 patients with LRR ENKTCL treated with re-irradiation or ChT alone

\begin{tabular}{|c|c|c|c|c|}
\hline $\begin{array}{l}\text { Clinical } \\
\text { features }\end{array}$ & Total & $\begin{array}{l}\mathrm{ChT} \\
\text { alone }\end{array}$ & $\begin{array}{l}\text { Re-irradiation } \\
\text { group }\end{array}$ & $p$-value \\
\hline Sex & & & & 0.508 \\
\hline Male & 23 & 13 & 10 & \\
\hline Female & 15 & 6 & 9 & \\
\hline Age & & & & 0.486 \\
\hline$\leq 60$ years & 36 & 19 & 17 & \\
\hline$>60$ years & 2 & 0 & 2 & \\
\hline B symptoms & & & & 0.746 \\
\hline With & 18 & 10 & 8 & \\
\hline Without & 20 & 9 & 11 & \\
\hline Primary sites & & & & 0.737 \\
\hline Nasal cavity & 24 & 11 & 13 & \\
\hline Others & 14 & 8 & 6 & \\
\hline ELTI & & & & 1.000 \\
\hline Yes & 17 & 8 & 9 & \\
\hline No & 21 & 11 & 10 & \\
\hline $\mathrm{LDH}$ & & & & 0.313 \\
\hline Elevated & 14 & 9 & 5 & \\
\hline Normal & 24 & 10 & 14 & \\
\hline $\begin{array}{l}\text { Ann Arbor } \\
\text { stage }\end{array}$ & & & & 0.447 \\
\hline IE & 29 & 13 & 16 & \\
\hline IIE & 9 & 6 & 3 & \\
\hline KPS score & & & & 1.000 \\
\hline 70 & 1 & I & 0 & \\
\hline$\geq 80$ & 37 & 18 & 19 & \\
\hline
\end{tabular}

Abbreviations: $\mathrm{ChT}$, chemotherapy; ELTI, extensive local tumor invasion; ENKTCL, extranodal natural killer/T-cell lymphoma, nasal type; KPS, Karnofsky Performance Score; LDH, lactate dehydrogenase; LRR, locoregionally recurrent.

and the overall 2-year survival rates from IT and after relapse were $89.5 \%$ and $84.2 \%$, respectively. The overall median follow-up time of the ChT only group from IT and after relapse was 28.4 months and 9.4 months, respectively. The overall 2-year survival rates from IT and after relapse were $76.2 \%$ and $47.8 \%$, respectively. Compared to ChT alone, re-irradiation improved the OS from IT $(p=0.018)$ (Figure 5A) and after relapse $(p=0.019)$ (Figure 5B).

\section{Univariate and multivariate analysis of OS after relapse}

According to the univariate and multivariate analyses, the following factors had an impact on the OS after relapse: the KPS score $(\mathrm{HR}=0.115,95 \% \mathrm{CI}=0.014-0.961)$, IT with or without RT $(\mathrm{HR}=4.862,95 \% \mathrm{CI}=1.340-17.645)$, and salvage treatment with or without RT $(\mathrm{HR}=4.220,95 \%$ $\mathrm{CI}=1.355-13.145$ ) (Table 3).

\section{Treatment-related toxicity of re-irradiation}

In the 19 patients with re-irradiation, there were 3 patients (15.7\%), 9 patients $(47.3 \%)$, and 7 patients $(37.0 \%)$ with acute grade 3 , grade 2 , and grade 1 mucositis, respectively. The acute dermatitis and salivary gland reactions were all grade 1; no grade 4 or higher cases of acute toxicity were observed. Late toxicity analysis was conducted for the patients with disease-free survival after relapse longer than 6 months. Nineteen patients were all included in the analysis; 3 (15.7\%) developed grade 3 toxicity, mainly cervical fibrosis and dental caries, with the remainder of patients having grade 1-2 toxicity, mainly for dry mouth and loss of gustatory sense. No cases of grade 4 or higher late toxicity were observed.

\section{Discussion}

In this study, the efficacy and prognosis of salvage treatment on ENKTCL in early stage locoregional relapse were analyzed. To our knowledge, this is the largest cohort of this subgroup of patients studied to date. The main conclusions are as follows: 1) relapse characteristics: local relapse is most common, followed by local relapse accompanied with
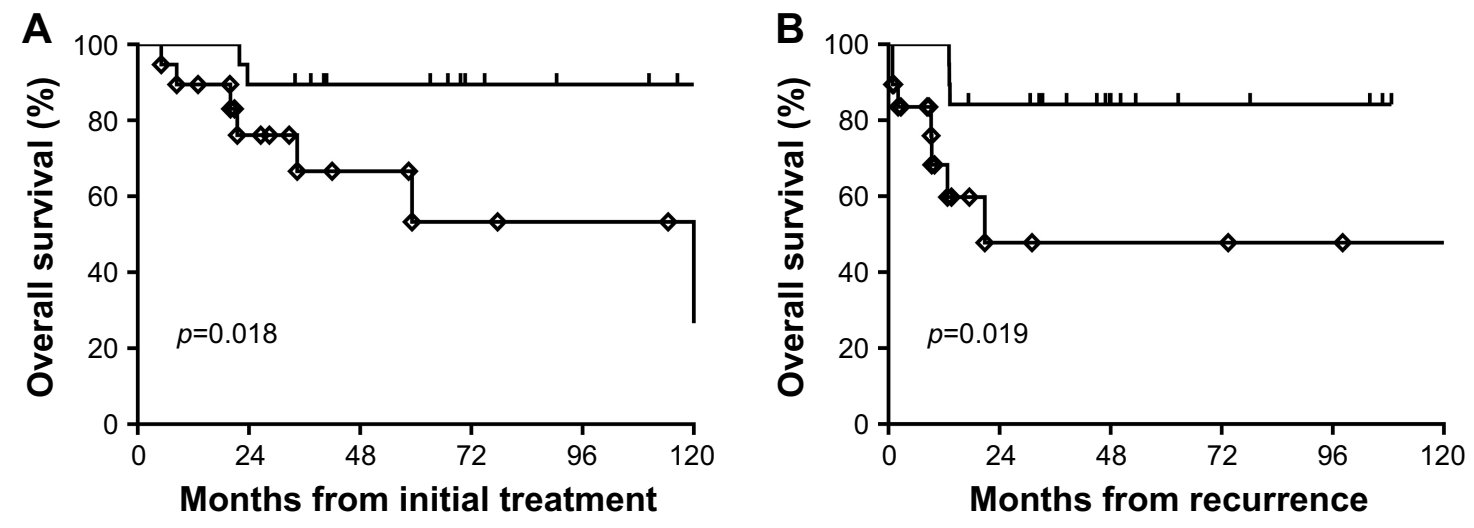

$\perp$ With re-irradiation

Without re-irradiation

Figure 5 Overall survival rates after initial treatment $(\mathbf{A})$ or after recurrence $(\mathbf{B})$ of 38 patients stratified by re-irradiation or lack thereof. 
Table 3 Univariate and multivariate prognostic analyses for OS-ar in overall 56 patients

\begin{tabular}{|c|c|c|c|c|}
\hline Factors & $\begin{array}{l}\text { 2-years } \\
\text { OS-ar (\%) }\end{array}$ & $\begin{array}{l}\text { 5-years } \\
\text { OS-ar (\%) }\end{array}$ & $\begin{array}{l}p \text {-value (log- } \\
\text { rank test) }\end{array}$ & $\begin{array}{l}p \text {-value (Cox } \\
\text { regression) }\end{array}$ \\
\hline Sex & & & 0.751 & 0.707 \\
\hline Male & 66.8 & 61.6 & & \\
\hline Female & 59.0 & - & & \\
\hline Age & & & 0.066 & 0.805 \\
\hline$\leq 60$ years & 68.9 & 61.9 & & \\
\hline$>60$ years & 33.3 & - & & \\
\hline B symptoms & & & 0.285 & 0.167 \\
\hline Yes & 67.8 & 61.0 & & \\
\hline No & 57.9 & 52.6 & & \\
\hline Primary sites & & & 0.831 & 0.235 \\
\hline Nasal cavity & 61.7 & 56.1 & & \\
\hline Others & 68.5 & 60.9 & & \\
\hline ELTI & & & 0.118 & 0.194 \\
\hline Yes & 49.9 & - & & \\
\hline No & 76.8 & 64.5 & & \\
\hline $\mathrm{LDH}$ & & & 0.977 & 0.869 \\
\hline Elevated & 72.8 & 50.9 & & \\
\hline Normal & 60.2 & - & & \\
\hline \multicolumn{2}{|c|}{ Ann Arbor stage } & & 0.860 & $0.035^{*}$ \\
\hline $\mathrm{IE}$ & 65.7 & 57.1 & & \\
\hline IIE & 58.2 & - & & \\
\hline KPS & & & $0.000^{*}$ & $0.046 *$ \\
\hline 70 & 0 & - & & \\
\hline$\geq 80$ & 72.4 & 60.2 & & \\
\hline IT & & & $0.030^{*}$ & $0.016 *$ \\
\hline With RT & 69.5 & - & & \\
\hline ChT alone & 49.0 & 24.5 & & \\
\hline CR after IT & & & 0.424 & 0.244 \\
\hline Yes & 75.3 & 63.2 & & \\
\hline No & 54.7 & - & & \\
\hline \multicolumn{3}{|c|}{ Duration of remission after IT } & 0.467 & 0.843 \\
\hline$\geq 2$ years & 67.1 & - & & \\
\hline$<2$ years & 63.2 & 53.6 & & \\
\hline \multicolumn{2}{|c|}{ Salvage treatment } & & $0.009 *$ & $0.013 *$ \\
\hline With RT & 79.9 & 70.7 & & \\
\hline ChT alone & 41.1 & - & & \\
\hline
\end{tabular}

Notes: $* p<0.05$. " - " indicated as missing data.

Abbreviations: ChT, chemotherapy; CR, complete remission; ELTI, extensive local tumor invasion; IT, initial treatment; KPS, Karnofsky Performance Score; LDH, lactate dehydrogenase; OS, overall survival; OS-ar, overall survival after relapse; $\mathrm{RT}$, radiotherapy.

regional lymph node relapse; simple regional lymph node relapse is rare. Relapse almost occurs within 2 years; longterm relapse (more than 5 years) is rare. 2) Salvage treatment: for the patients with locoregional relapse, the potential role of salvage RT or re-irradiation is more important than $\mathrm{ChT}$ alone. Furthermore, the toxicity of the re-irradiation is also acceptable. 3) Prognostic factors: the addition of RT to the IT and salvage treatment can improve the OS and prognosis after relapse. KPS score is also an important prognostic factor - the higher the score, the better prognosis.

A number of studies have shown that relapse of ENKTCL in the early stage is rare at regional lymph nodes and common at local areas ${ }^{9-11}$ and that the relapses mainly occur within 2 years. ${ }^{9-12}$ These findings are consistent with our results. Long-term relapse is rare, but still exists. A study reported that the patient's whole body symptoms during the initial diagnosis are independent risk factors for long-term relapse. ${ }^{13}$ For the short-term relapse factors, it has been reported that receiving small-field and low-dose radiation can cause the locoregional relapse rate to be as high as $50 \%{ }^{4,14-16} \mathrm{An}$ insufficient radiation dose can lead to in-field and edge relapse; nearby out-field relapse is related to incomplete target coverage. Currently, high doses and extended field radiation are recommended for the treatment of ENKTCL in the early stage to reduce the short-term relapse., ${ }^{717}$ There is a study reported that relapse is further classified as true relapse, edge relapse, and other relapse. ${ }^{11}$ For example, there are 2 patients in this study whose primary sites were the nasal cavity. The first relapse was in situ (in-field) relapse and was treated with re-irradiation; the second relapse was laryngeal relapse that was treated with third-course RT. One of the patients had a third relapse at the skin on the sternoclavicular joint plane; after fourth-course RT, the relapse was under control. These patients showed repeated local relapse, as opposed to most patients with local relapse who progress to distant metastasis. It is unclear whether this type of relapse is relatively inert, has better prognosis, and is related to heterogeneity of the disease. A small sample study found that Ki67 in these patients was in a low expression state, ${ }^{18}$ but the specific mechanism is not yet clear.

Previous studies suggest that for relapse or treatmentresistant ENKTCL, prognosis is poor, and no standard treatment has been established. The reasons for this may be as follows: 1) ENKTCL is a ChT-resistant cancer, and even when using L-asparaginase-based regimens, the median survival time is approximately 1 year, ${ }^{19}$ with a 1 -year OS rate of $55 \%{ }^{20}$ for patients with relapse or who are treatmentresistant. 2) For patients with initially treated by RT, based on re-irradiation sensitivity and tolerance of the head and neck normal tissue, the majority of doctors are cautious of re-irradiation after relapse. Effective means of treatment for patients with relapse seem limited, and only a few studies have explored salvage treatment after relapse. Zhang et al ${ }^{12}$ reported 16 patients with locoregional relapse of ENKTCL; after salvage treatment (13 cases), the total 5-year survival rate was $62.5 \%$, and no significant difference in the 3-year OS rate was identified between the ChT group ( 9 cases) and the no ChT group (7 cases). This finding showed that salvage ChT has little effect on survival. In addition, the study indirectly indicated that RT is the main factor improving the 
survival of patients rather than $\mathrm{ChT}$. Zhao et $\mathrm{al}^{9}$ reported that for 29 patients with locoregional relapse of ENKTCL, the total 2-year survival rates after relapse were $77 \%$ in the RT group (19 cases) and 50\% in the no RT group (10 cases). For 24 patients with relapse after the IT of RT, the overall 2-year survival rates after relapse were $85 \%$ in the re-irradiation group ( 15 cases) and 30\% in the ChT group ( 9 cases); the difference was statistically significant. This study directly confirms the effect of RT in the salvage treatment. The number of cases in our study was significantly larger. A total of 56 patients were included; the overall 3-year survival rate for the whole group was $72.7 \%$, and the OS rate after relapse was $57.8 \%$. According to the subgroup analysis, the overall 3-year survival rate from IT was $84.0 \%$ in the salvage RT group, and the OS rate after relapse was 70.7\%. The overall 2-year survival rate from IT was $89.5 \%$ in the re-irradiation group, and the OS rate after relapse was $84.2 \%$. These data are even close to the survival rate of patients with the RT-based IT of ENKTCL in the early stage. The survival rate of the RT group and re-irradiation group was significantly higher than that of the ChT alone group; the difference was statistically significant. This finding also suggests that RT was the main factor to improve the survival.

In addition, this study shows that the efficacy $(\mathrm{CR}+\mathrm{PR})$ of re-irradiation for ENKTCL with locoregional relapse was $100 \%$, which indicates that the disease is still sensitive, and this finding is similar to previous reports. ${ }^{9,13}$ In addition, the study also shows that the toxicity for most of the re-irradiation was grades 1-2; no grade 4 or higher toxicity was observed, which is a benefit of the use of 3-dimensional or intensity-modulated RT technology. ${ }^{7,17}$ In the prognostic factor analysis, the impact of the treatment model on the survival was confirmed once again. Applying RT in the initial and salvage treatment had an impact on the OS after relapse, and the outcome of the RT group was better than that of the ChT alone group. In addition, KPS is also a prognostic factor; other indicators, such as age, LDH, staging, and B symptoms in the International Prognostic Index (IPI) score, did not show an impact on survival in this study, similar to the findings reported by Zhang et al. ${ }^{12}$ Therefore, whether the IPI score can be used to instruct the prognosis of ENKTCL still needs to be determined. The importance of additional potential prognostic indicators, such as Epstein-Barr virus DNA copy number and molecular classification, remains to be further studied.

\section{Conclusion}

The results of this study suggest that RT and re-irradiation are necessary for the salvage treatment of locoregional relapse in
ENKTCL. This approach can improve survival, with acceptable treatment toxicity. However, this study was a retrospective analysis and may be biased in the treatment options and has a small sample size. In addition, because of the small sample size, it did not further subdivide the salvage RT group into IT without RT, in-field relapse after RT, and out-field relapse after RT groups, which could explain the value of salvage RT better. We look forward to the results of a prospective randomized multi-center clinical trial with a large sample size.

\section{Disclosure}

The authors report no conflicts of interest in this work.

\section{References}

1. Fang H, Jin J, Wang WH, Wang SL, Zhou LQ, Li YX. Prognostic factors and treatment outcomes for patients with stage II extranodal nasal-type natural killer/T-cell lymphoma of the upper aerodigestive tract. Leuk Lymphoma. 2014;55(8):1832-1837.

2. Zhang J, Zhu MY, Wang L, et al. "Sandwich" Chemotherapy (CT) with Radiotherapy (RT) improves outcomes in patients with stage IE/IIE extranodal natural killer (NK)/T-cell Lymphomas. Asian Pac J Cancer Prev. 2013;14(7):4061-4066.

3. Avilés A, Neri N, Fernández R, Huerta-Guzmán J, Nambo MJ. Combined therapy in untreated patients improves outcome in nasal NK/T lymphoma: results of a clinical trial. Med Oncol. 2013;30(3):637.

4. Li YX, Liu QF, Wang WH, et al. Failure patterns and clinical implications in early stage nasal natural killer/T-cell lymphoma treated with primary radiotherapy. Cancer. 2011;117(22):5203-5211.

5. Kim K, Chie EK, Kim CW, Kim IH, Park CI. Treatment outcome of angiocentric T-cell and NK/T-cell lymphoma, nasal type: radiotherapy versus chemoradiotherapy. Jpn J Clin Oncol. 2005;35(1):1-5.

6. Yang Y, Zhang Y, Lin X, et al. Role of radiotherapy in the combined treatment of patients with early stage extranodal nasal type NK/T-cell lymphoma and analysis of prognostic factors. Chin J Radiat Oncol. 2009; 18(4):285-289.

7. Niu S, Zhang Y, Wen G, et al. Preliminary results of a phase II prospective clinical study of early-stage nasal NK/T-cell lymphoma with extended involved-field intensity-modulated radiotherapy. Chin $J$ Radiat Oncol. 2015;(4):377-381.

8. Cheson BD, Horning SJ, Coiffier B, et al. Report of an international workshop to standardize response criteria for non-Hodgkin's lymphomas. NCI Sponsored International Working Group. J Clin Oncol. 1999; 17:1244-1253.

9. Zhao T, Li YX, Wang SL, et al. Survival benefit with salvage radiotherapy for patients with locoregionally recurrent extranodal NK/T cell lymphoma, nasal type. Ann Hematol. 2013;92(3):325-332.

10. Li CC, Tien HF, Tang JL, et al. Treatment outcome and pattern of failure in 77 patients with sinonasal natural killer/T-cell or T-cell lymphoma. Cancer. 2004;100(2):366-375.

11. Koom WS, Chung EJ, Yang WI, et al. Angiocentric T-cell and NK/Tcell lymphomas: radiotherapeutic viewpoints. Int J Radiat Oncol Biol Phys. 2004;59(4):1127-1137.

12. Zhang XX, Xie CH, Xu Y, et al. Salvage treatment improved survival of patients with relapsed extranodal natural killer/t-cell lymphoma, nasal type. Int J Radiat Oncol Biol Phys. 2009;74(3):747-752.

13. Chen B, Li Y, Liu Q, et al. Analysis of risk factors for late relapse in earlystage extranodal nasal-type NK/T-cell lymphoma after treatment. Chin J Radiat Oncol. 2013;22:175-179. Available from: http://www.wanfangdata. com.cn/details/detail.do?_type=perio\&id=zhfszl201303001. Accessed February 03, 2018. 
14. Ma HH, Qian LT, Pan HF, et al. Treatment outcome of radiotherapy alone versus radiochemotherapy in early stage nasal natural killer/T-cell lymphoma. Med Oncol. 2010;27(3):798-806.

15. Lee J, Cho SG, Chung SM, et al. Retrospective analysis of treatment outcomes for extranodal NK/T-cell lymphoma (ENKL), nasal type, stage I-IIE: single institute experience of combined modality treatment for early localized nasal extranodal NK/T-cell lymphoma (ENKL). Ann Hematol. 2013;92(3):333-343.

16. Yamaguchi M, Tobinai K, Oguchi M, et al. Phase I/II study of concurrent chemoradiotherapy for localized nasal natural killer/T-cell lymphoma: Japan Clinical Oncology Group Study JCOG0211. J Clin Oncol. 2009;27(33):5594-5600.

17. Wang H, Li YX, Wang WH, et al. Mild toxicity and favorable prognosis of high-dose and extended involved-field intensity-modulated radiotherapy for patients with early-stage nasal NK/T-cell lymphoma. Int J Radiat Oncol Biol Phys. 2012;82(3):1115-1121.
18. Kim SJ, Park Y, Kim BS, Kim I, Ko YH, Kim WS. Extranodal natural killer/T-cell lymphoma with long-tem survival and repeated relapses: does it indicate the presence of indolent subtype? Korean J Hematol. 2012;47(3):202-206.

19. Jaccard A, Gachard N, Marin B, et al; GELA and GOELAMS Intergroup. Efficacy of L-asparaginase with methotrexate and dexamethasone (AspaMetDex regimen) in patients with refractory or relapsing extranodal NK/T-cell lymphoma, a phase 2 study. Blood. 2011;117(6): 1834-1839.

20. Yamaguchi M, Kwong YL, Kim WS, et al. Phase II study of SMILE chemotherapy for newly diagnosed stage IV, relapsed, or refractory extranodal natural killer (NK)/T-cell lymphoma, nasal type: the NK-Cell Tumor Study Group study. J Clin Oncol. 2011;29(33):4410-4416.

\section{Publish your work in this journal}

Therapeutics and Clinical Risk Management is an international, peerreviewed journal of clinical therapeutics and risk management, focusing on concise rapid reporting of clinical studies in all therapeutic areas outcomes, safety, and programs for the effective, safe, and sustained use of medicines. This journal is indexed on PubMed Central, CAS,
EMBase, Scopus and the Elsevier Bibliographic databases. The manuscript management system is completely online and includes a very quick and fair peer-review system, which is all easy to use. Visit http://www.dovepress.com/testimonials.php to read real quotes from published authors. 